\title{
Clinicians' satisfaction with a hospital blood transfusion service: a marketing analysis of a monopoly supplier
}

\author{
S J Pennington, D B L McClelland, W G Murphy
}

\begin{abstract}
One of the objectives of the NHS reforms is to improve customer focus within the health service. In a study to assess the quality of customer service provided by the Edinburgh and South East Scotland Blood Transfusion Service a 19 item questionnaire survey of the main clinical users of the service was performed to ascertain their satisfaction, measured on a 5 point anchored scale, with important aspects of the service, including medical consultation, diagnostic services, blood and blood components or products and their delivery, and general satisfaction with the service. Of 122 clinicians in medical and surgical disciplines in five hospitals in Edinburgh, 72(59\%) replied. Fourteen $(22 \%)$ indicated dissatisfaction with any aspect of the medical consultation service, owing to inadequate follow up of clinical contacts and unsatisfactory routing of incoming calls. Diagnostic services were criticised for the presentation, communication, and interpretation of results. The restricted availability of whole blood, the necessity to order platelets and plasma through the duty blood transfusion service doctor, and the use of a group and screen policy, attracted criticism from a small number of clinicians. Ten of 68 respondents expressed dissatisfaction with delivery of blood and components to the wards and theatres. The findings indicate that the clinicians served by this blood transfusion service are largely satisfied with the service. Changes are being implemented to improve reporting of laboratory results and measures taken to improve liaison with clinicians.
\end{abstract}

(Quality in Health Care 1993;2:239-242)

One result of the new purchaser-provider relationship in part of the NHS is a move towards a service marketing approach by providers. This implies an increased emphasis on consumers' needs and demands for services ${ }^{1}$ and adoption of a customer centred marketing approach in which the NHS becomes fully responsive to customers' needs by making every effort to sense, serve, and satisfy them. ${ }^{2}$ The 1989 white paper on the health service set several objectives for the NHS, including increased NHS responsiveness to client groups. ${ }^{3}$ This need was first identified in the Griffiths report on general management in the NHS, in which the inquiry team identified a lack of concern for views of consumers. ${ }^{4}$

To address some of these issues we performed a customer satisfaction survey of clinicians who request blood products or diagnostic and clinical services from the Edinburgh and South East Scotland Blood Transfusion Service.

\section{Methods}

We performed the survey from August 1991 to October 1991, administered in the form of a postal questionnaire to clinicians of all grades in five hospitals in Edinburgh. The clinicians were chosen for inclusion on the basis of their high usage of the blood transfusion service, especially hospital blood banking, and they were identified from the blood bank records as being associated with the surgical, medical, and obstetric units that most frequently ordered blood and blood components. About half the surgical, anaesthetic, medical, and obstetric consultants within the clinical units served by the blood bank were identified in this high usage group.

The questionnaire was formulated with the methods of Oppenheim. ${ }^{5}$ Attitudinal response and ranking of factors questions were used, with an anchored 5 point scale that involved subjects indicating their attitudes to each statement, varying from, for example, "strongly agree" (score 5) to "strongly disagree" (score 1), as well as factual and numerical questions (box). Spaces were available for written comments. Clinicians were regarded as indicating some dissatisfaction with an aspect of service if they gave a score of 1 or 2 . A pilot study was performed by conducting a structured interview in which the researcher went through the initial questionnaire individually with eight clinicians. The full survey was performed in October 1991 with a slightly modified questionnaire.

The responses were analysed with the statistical package for social sciences (SPSS) program on a Vax cluster with a Fortran controller. Frequency counts for responses 
Edinburgh and South East Scotland Blood Transfusion Service

Survey of blood transfusion service (BTS) service provision
1 a) Name
b) Ward/dept
2 a) Hospital
b) Grade and specialty

3 Which of the following services of BTS do you use?

a) Blood Products (specified in full)

b) Diagnostic Services (specified in full)

c) Consultation

YOUR OPINION OF BTS SERVICES/PRODUCTS

How much do you agree with the following statements?

4 With regard to telephone answering you receive:

a) Prompt pick up

b) Informed receptionist

c) Courteous service

d) Rapid through connection to required extension

$\begin{array}{ccccc}\text { Disagree } & & & & \begin{array}{c}\text { Strongly } \\ \text { agree }\end{array} \\ 1 & 2 & 3 & 4 & 5 \\ 1 & 2 & 3 & 4 & 5 \\ 1 & 2 & 3 & 4 & 5 \\ 1 & 2 & 3 & 4 & 5\end{array}$

How do you rate the following services/products?

5 For red cell products please rate:

a) BTS provision policies:

eg Availability of whole blood or autologous transfusion

Surgical blood ordering schedule

Blood bank routine working hours

Sample labelling requirements

b) BTS response time

c) BTS delivery procedure

d) Standard of provided products

(NB Repeated for other products as questions 6 to 9 in same way)

\begin{tabular}{ccccc}
$\begin{array}{c}\text { Not very } \\
\text { satisfactory }\end{array}$ & & \multicolumn{2}{c}{$\begin{array}{c}\text { Very } \\
\text { satisfactory }\end{array}$} \\
1 & 2 & 3 & 4 & 5
\end{tabular}

RANKING OF DIAGNOSTIC SERVICES PROVISION

Indicate your opinion of the following services

10 BTS provides a suitable range of laboratory services for your needs

11 BTS response time when performing testing meets your requirements

12 BTS provides ordering methods that are adequate for your needs

13 BTS ensures a satisfactory supply of sample tubes

14 BTS laboratory working hours are suitable for your requirements

15 When relaying the results of testing BTS provides:

a) Suitably detailed form

b) Clear presentation

c) Adequate interpretation/comment on results

d) Adequate information about normal ranges

16 BTS provides a consultation service through a duty doctor who:

a) Is readily available

b) Provides useful clinical advice

c) Provides adequate follow up

Ver

Very
good

$\begin{array}{lllll}1 & 2 & 3 & 4 & 5\end{array}$

$\begin{array}{lllll}1 & 2 & 3 & 4 & 5\end{array}$

$\begin{array}{lllll}1 & 2 & 3 & 4 & 5\end{array}$

$\begin{array}{lllll}1 & 2 & 3 & 4 & 5 \\ 1 & 2 & 3 & 4 & 5\end{array}$

Have any recent changes in BTS policies caused you:

a) Any concern?

b) Any inconvenience?

c) Any confusion?

Yes / No

Yes / No

Yes / No

18 How often are your regular dealings with BTS completed satisfactorily?

$\begin{array}{ccccc}\text { Never } & & & & \text { Always } \\ 1 & 2 & 3 & 4 & 5\end{array}$

19 It would be appreciated if you would comment on any elements/parts of the BTS service not covered in this questionnaire that you consider relevant to the study of service provision.

were obtained and cross tabulations made when appropriate.

\section{Results}

Questionnaires were dispatched to 122 clinicians who were identified as being high users of the service, and 72 were returned (overall response rate 59\%); non-responders were not pursued further in this study. No obstetric consultants completed the survey, but otherwise all clinical specialties were represented in the finished survey. Senior clinicians (consultants and senior registrars) were more heavily represented among the respondents than junior clinicians (registrars and house officers) $(66 \%, 45 / 68 v 50 \%, 27 / 54$ (table)).

Medical consultation service

The blood transfusion service provides a 
Number of questionnaires by clinician grade

\begin{tabular}{lcc}
\hline Clinician grade & No sent & No (\%) returned \\
\hline Consultant & 52 & $33(63)$ \\
Senior registrar & 16 & $12(75)$ \\
Registrars & 35 & $20(57)$ \\
House officers $^{\star}$ & 19 & $7(37)$ \\
\hline Total & 122 & $72(59)$ \\
\hline
\end{tabular}

^Including senior house officers.

medical consultation service related to the provision of blood products - for example, an on call clinical consultation service. This service was used by $89 \%(64 / 72)$ of the respondents, $22 \%(14 / 64)$ of whom expressed some dissatisfaction with this service, particularly regarding clinical follow up, in their replies. Clinical advice was reported to be quite satisfactory (mean value $4 \cdot 23$ (SD $0 \cdot 77$ )), and some comments indicated that it was highly valued. However, four clinicians had difficulty with the availability of the service (mean value $4 \cdot 08(0 \cdot 86)$ ); allied to this was the finding that telephonists did not always route calls satisfactorily (mean value $3.97(0 \cdot 76)$ ). Additionally $13 \%(8 / 64)$ of clinicians expressed dissatisfaction with the degree of follow up provided by the doctors in the blood transfusion service (mean value $3 \cdot 56(1 \cdot 13)$ ).

\section{Diagnostic services}

The blood transfusion service also provides several diagnostic services to clinicians - for example, an antenatal serology service. Clinicians were generally quite satisfied with the range, response time, request schedule, and availability of these services (mean values $\geqslant 4 \cdot 2$ ), although six of the 61 respondents who used these services suggested the need for their availability to be extended. Clinicians were less satisfied with the communication of results by the diagnostic services. The reporting of results on forms was satisfactory (mean value $4 \cdot 1(0 \cdot 72)$ ) but the presentation of results could be improved (mean value $4 \cdot 0(0 \cdot 93))$. Interpretation and comment on the results in the test reports were not considered satisfactory by $10 \%(6 / 61)$ of respondents (mean value $3 \cdot 8(0 \cdot 94)$ ). More information on normal ranges (mean value $3.8(0.92)$ ) was required by $7 \%(4 / 61)$ of respondents, particularly by anaesthetists who were in general significantly less satisfied with the information provided than respondents in other specialties $(p<0.05)$.

\section{Blood, blood components, and blood platelets}

Hospital blood banking services are provided directly by the blood transfusion service to the hospitals in the survey. Red cells for transfusion were used by $99 \%(71 / 72)$ of clinicians, and speed of response, provision, and standard of this product were satisfactory (mean values $>4 \cdot 1$ ). Seventeen clinicians (24\%) added comments, seven concerned with policies on providing red cells. Five clinicians wanted whole blood readily available for infusion whereas two expressed unease over possible delays arising from the red cell group and save policy. Among products provided other than red cells, including fresh frozen plasma, cryoprecipitate, platelets, intravenous IgG, albumin, and clotting factors, quality of product, ordering policies, and response times to requests were generally satisfactory (all scores $>4 \cdot 0$ ). However, $14 \%$ of clinicians (9/66) were dissatisfied with the ordering policies for platelets, fresh frozen plasma, and cryoprecipitate.

\section{Delivery}

The delivery of blood and components was an area of considerable dissatisfaction to clinicians. Ten of 71 respondents were dissatisfied (scores of 1 or 2 ) with delivery procedures for red cells (mean value $3 \cdot 7(1 \cdot 03)$ ) and seven of $66(11 \%)$ users were dissatisfied with the delivery procedures for fresh frozen plasma, platelets, and cryoprecipitate (mean value $3 \cdot 8(0 \cdot 98)$ ). Clinicians commented that the poor delivery was not directly seen as a failing of the blood transfusion service.

\section{General satisfaction}

Clinicians were generally satisfied with their transactions with the service, with one, three, 42, and 22 clinicians scoring 2, 3, 4, and 5 respectively (mean value $4 \cdot 25(0 \cdot 61)$ ). Thus $94 \%$ of clinicians were at least quite satisfied with the outcomes of their transactions; six clinicians made comments indicating that they received an excellent service.

\section{Discussion}

Audit studies have repeatedly shown that the use of blood products often fails to comply with existing clinical guidelines. ${ }^{6-9}$ Concern about inappropriate use of blood products has often led blood bank services and transfusion services to adopt rather restrictive policies, rather than accept the view that "the customer knows best." It is, however, more appropriate that clinicians responsible for individual patients should have their needs identified and met by the transfusion service and that audit and education should be the main instruments of achieving appropriate use of blood products. The study described here was undertaken as part of a programme to identify opportunities to improve the service provided to clinicians.

With the anchored 5 point scoring system used $^{5}$ it is important to emphasise that the presence of any low values suggests a failure, at least in some instances, to achieve a satisfactory standard of customer service. As a consequence, the value of the overall mean in itself cannot be taken as fully representative of the satisfactory provision of goods and services: the tabulation of results must also be examined. The presence of low scores is particularly important to a monopoly provider. Where there is a choice of suppliers dissatisfied consumers have the opportunity to go elsewhere. No such signal of dissatisfaction is available to consumers of a monopoly provider's services.

Seventy two of 122 clinicians responded to the questionnaire, and in view of the high turnover of junior medical staff no follow up of 
non-responders was attempted. The response rate was lowest among junior staff: this may be attributable to a lower expectation of benefit from participation in such a survey. In future surveys it will be necessary to pay particular attention to the needs and perceptions of junior medical staff.

The transaction between the blood transfusion service and clinicians entails both the supply of products and also the services which accompany them. All elements of the market entity (that is, product and associated services combined) need to be carefully managed if clinicians are to be satisfied. The medical consultation service attracted a fair degree of adverse reaction. In addition, conveying diagnostic test results was a particular area of dissatisfaction, apparently due to suboptimal communications between the transfusion service and clinicians. Ten per cent of clinicians were dissatisfied owing to the lack of sufficient interpretative information they received on test reports. The delivery of blood products was also perceived to have shortcomings.

Policies for providing blood components also provoked some dissatisfaction. Several clinicians expressed a clear wish to have whole blood more readily available for infusion, particularly in theatre, because they regard it as better than red cell concentrate. There have been no adequate objective studies to show clear clinical advantage of whole blood over red cell concentrate. The use of red cell concentrate has greatly improved the benefit derived from blood donations by allowing plasma to be collected cost effectively. This allows for improved use of health care resources, particularly in providing plasma derived products such as factor VIII, albumin, and immunoglobulins. The blood transfusion service therefore must meet conflicting demands: those of its clinical customers and those of providing maximal health care benefit to the entire community for its available resources. A continuing process of medical audit and education may contribute to the resolution of these conflicts.

Our findings indicate that this group of clients are largely satisfied with the service they receive. However, they may be intuitively comparing the blood transfusion service with their experiences of professional bureaucracies, ${ }^{10}$ rather than with an ideal blood transfusion service or other laboratory service when making their assessment.

Organisations have to cope with the complexity, hostility, unforeseen traumas, vagaries, and opportunities that are generated by their environment. A strong customer orientation provides a means of survival in such a turbulent and competitive market environment. ${ }^{11}$ The marketing concepts embodied in the white paper ${ }^{1}$ have a role in strategic planning. Yet adopting a customer orientation does not mean allowing clients wants and needs to dictate strategy. ${ }^{12}$ Such decisions in any organisation are rarely made by focusing on a single group's interests. Customer orientation should ensure that all who should be heard, because they have a stake in the activity, will be identified and given a voice in the accommodation process associated with strategic decisions. Thus this marketing activity should ensure that all factors are taken into consideration in the strategic decision making process.

Since the completion of this survey this blood transfusion service has introduced changes in the reporting of diagnostic results and concentrated on improving medical liaison. A rolling customer feedback programme has been put in place and a comprehensive customer database has been set up. In addition, the scope of customer analysis has been widened to include patients being treated with products, provided by the blood transfusion service.

Marketing concepts can help a blood transfusion service to fulfil its organisational goals by enabling it to identify the factors in the environment to which it needs to respond. They should also help it to comply with the demands imposed by the reforms introduced by the white paper.

We thank Mrs $M$ Stone, lecturer in marketing in the Department of Business Organisation, Heriot-Watt University, for her help and that of her computer support staff in the performance of this study.

1 Barrett V. The customer imperative. International fournal of Health Care Quality Assurance 1991;4:5-10.

2 Kotler P, Andreasen AR. Strategic marketing for non-profit organisations. 3rd ed. New Jersey: Prentice Hall, 1985.

3 Secretaries of State for Health, Wales, Northern Ireland, and Scotland. Working for patients. London: HMSO, 1989. (Cm 555.)

4 Griffiths R. NHS management inquiry. London: Department of Health and Social Security, 1983.

5 Oppenheim AN. Questionnaire design and attitude measurement. London: Heinemann, 1980.

6 Mozes.B, Epstein M, Ben-Bassat B, Modan B, Halkin H Evaluation of the appropriateness of blood and blood product transfusion using pre-set criteria. Transfusion 1989;29:473-6.

7 Thomson A, Contreras M, Knowles S. Blood componen treatment: a retrospective audit in five major London hospitals. F Clin Pathol 1991;44:734-7.

8 Giovanetti AM, Parravicini L, Riccardi D, Pizzi MN, Almini D, Sirchia G. Quality assessment of transfusion practice in elective surgery. Transfusion 1988;28:166-9.

9 McCullough J, Steeper TA, Connelly DP, Jackson B, Huntington S, Scott EP. Platelet utilization in a Huntington $S$, Scott EP. Platelet utiliza
university hospital. $¥ A M A 1988 ; 259: 2414-8$.

10 Mintzberg $H$. The structuring of organizations. New Jersey: Prentice Hall, 1979.

11 Brownlie D. Environmental scanning. In: Baker MJ, ed. The marketing book. 2nd ed. London: ButterworthHeinmann, 1991:101-27.

12 Bailey D. Dynamic inertia: why $90 \%$ of customer service programmes fail. Transition 1992;92:17-9. 